\title{
Attitude to Secondary Prevention and Concerns about Colonoscopy Are Independent Predictors of Acceptance of Screening Colonoscopy
}

\author{
Matthias Ziegler ${ }^{\mathrm{a}}$ Bodo Schubring-Giese ${ }^{\mathrm{b}}$ Markus Bühner ${ }^{\mathrm{c}}$ \\ Frank Thomas Kolligs ${ }^{b}$ \\ a Institute of Psychology, Faculty of Mathematics and Natural Sciences II, Humboldt-Universität zu Berlin, Berlin, \\ ${ }^{b}$ Department of Medicine II, Faculty of Medicine, and ' ${ }^{\mathrm{C}}$ Department of Psychology, Faculty of Psychology and \\ Pedagogics, University of Munich, Munich, Germany
}

Key Words

Colorectal cancer $\cdot$ Colonoscopy $\cdot$ Screening

\begin{abstract}
Background: Colonoscopy in combination with endoscopic polypectomy has been shown to be an efficient measure for reducing colorectal cancer incidence. In Germany, a colorectal cancer screening program based on colonoscopy for individuals aged 55 and above was introduced in 2002. However, for largely unknown reasons, participation rates remain low. The purpose of this study was to identify factors influencing compliance with colorectal cancer screening. Methods: A structured survey of 239 individuals aged $55-79$ years was performed. Statistical analysis included $\chi^{2}$ test, $t$ test, principal component analysis, and logistic regression. $\boldsymbol{R e}$ sults: $56 \%$ of previously screened, but only $26 \%$ of nonscreened individuals had received a recommendation to undergo screening colonoscopy. $50 \%$ of the non-screened believed a screening colonoscopy should only be performed in case of complaints. Univariate analysis identified participation in any secondary prevention measures $(p<0.001)$, concerns about colonoscopy $(p<0.012)$, and knowledge about colorectal cancer $(p<0.001)$ as critical issues distinguishing between groups. Multivariate analysis revealed that secondary prevention $(p<0.001)$ and concerns about
\end{abstract}

colonoscopy ( $p=0.026$ ) were independent predictors of compliance with screening recommendations. Conclusion: Our survey has identified critical factors deterring compliance with colorectal cancer screening recommendations. This will help to direct future campaigns in order to increase participation in colorectal cancer screening.

Copyright $\odot 2010$ S. Karger AG, Basel

\section{Introduction}

Colorectal cancer is the third most common cancer, the third leading cause of cancer death, and accounts for approximately $10 \%$ of cancer deaths overall [1]. Approximately 1 in 3 people who develop colorectal cancer ultimately die of the disease. Early detection and removal of adenomatous polyps has been shown to reduce the risk for colorectal cancer [2,3]. Although no randomized controlled trials or case-control studies to demonstrate the effectiveness of colonoscopy as a screening test on colorectal cancer mortality have been performed, several crosssectional studies have demonstrated that screening using colonoscopy in asymptomatic persons with average risk has a higher sensitivity for adenomatous lesions and early cancer than fecal occult blood test (FOBT) and sigmoidoscopy [2-7]. Therefore, several guidelines endorse

\section{KARGER}

Fax +4161306 1234 E-Mail karger@karger.ch www.karger.com
(C) 2010 S. Karger AG, Basel

$0012-2823 / 10 / 0812-0120 \$ 26.00 / 0$

Accessible online at:

www.karger.com/dig
Frank Thomas Kolligs

Department of Medicine II, Klinikum Grosshadern, University of Munich

Marchioninistrasse 15, DE-81377 Munich (Germany)

Tel. +49 897095 2272, Fax +49 8970955271

E-Mail fkolligs@med.uni-muenchen.de 
colonoscopy every 10 years as the preferred screening measure in average-risk individuals [8-11]. In Germany, a nationwide colonoscopy-based screening program was enacted in 2002 starting at the age of 55.

The German screening program is well documented [12]. In 2006, 529,916 individuals underwent screening colonoscopy within the program. $98.4 \%$ of the colonoscopies were documented as complete. A total of 5,240 asymptomatic colorectal cancers, in the majority of cases in a favorite tumor stage, were detected. Altogether, in 2006, 145,539 polypectomies were performed and $6.7 \%$ of screeners revealed an advanced adenoma (size $\geq 1 \mathrm{~cm}$, villous architecture, high-grade intestinal neoplasia). The overall complication rate with 2.6 per 1,000 colonoscopies was low. Despite the high efficacy and safety of screening, colonoscopy acceptance within the general population remains low with cumulative participation rates of 11.2 and $12.7 \%$ of eligible men and women, respectively, between 2003 and 2006 . Within a time frame of 10 years a total participation rate of $20-30 \%$ has been estimated.

As compliance has been found to be the single most important determinant of effectiveness of screening programs [13], identifying factors influencing acceptance of screening colonoscopy is essential in order to increase adherence to the German program. This survey identifies demographic factors and determinants of participation in screening colonoscopy in uni- and multivariate analyses. These results will help to focus campaigns intending to raise participation rates in colonoscopy screening.

\section{Materials and Methods}

\section{Development and Structure of the Questionnaire}

The survey assessed demographic characteristics, knowledge about and factors influencing adherence to colorectal cancer screening. For the construction of the questionnaire, surveys from other studies [14-16] were reviewed and open interviews with primary physicians, internists, and gastroenterologists about factors influencing participation in colonoscopy screening were performed. A first version of the questionnaire was developed which contained a wide array of potentially influencing factors. In order to refine the set of questions and test for understanding as well as practicability of the questionnaire, a pilot survey with 30 interviews was conducted. The results of the pilot study were used to modify questions and to calculate the sample size needed. The final version of the questionnaire consisted of 63 items covering such topics as (1) knowledge about colorectal cancer and colorectal cancer screening, (2) attitude to healthy lifestyle and prevention, (3) colonoscopy-related questions as well as (4) demographic questions. All questionnaires contained the same questions except for some of the colonoscopy-related questions, which were modified according to the individual status of having undergone screening colonoscopy. Participants with previous screening colonoscopies were asked which factors had influenced their decision to undergo screening colonoscopy, whereas those without screening colonoscopies were asked for factors responsible for their non-participation. The full questionnaire will be made available upon request.

Identification of Study Subjects, Data Collection and Analysis To plan sample size, results from 30 test interviews were used. The average effect size found between persons who previously had a screening colonoscopy and those who did not was Cohen's $\mathrm{d}=$ 0.35 . In a setting of $\alpha=0.05$ and $\beta=0.20$, each group was calculated to require a number of 102 interviews. Random-digit dialed telephone surveys were performed in the city and surrounding area of Munich, Germany (area code 89), in July and August 2007. A total of 2,619 telephone numbers were dialed until the sample size in each group was sufficient. In case no connection could be established, the same number was dialed again later for up to five times. Interviews were only started if the respondent was between 55 and 79 years of age. Of the 728 persons agreeing to proceed with the interview, 308 (42\%) were between 55 and 79 years of age. The interviews lasted between 7 and $10 \mathrm{~min}$. Answers were documented electronically during the interviews (ttCall Version 3.0; Tribe Technologies, Frankfurt, Germany).

\section{Statistical Analysis}

Statistical analysis was performed using SPSS Version 16.0 (SPSS, Inc., Chicago, Ill., USA). Because the study aimed at comparing individuals with and without prior screening colonoscopy, group membership served as independent variable in a series of $\chi^{2}$ tests with demographic variables as dependent variables. Age differences were analyzed by $t$ test for independent samples. In order to identify factors for non-participation in the screening colonoscopy program, differences in all items were compared between both groups. Prior to analysis, answers to questions with 4-point-rating scales were recoded to obtain a dichotomous answer. The answer categories 'totally disagree' and 'disagree' were combined as well as the answer categories 'agree' and 'fully agree'. For a principal component analysis (PCA) of uncorrelated factors a Varimax rotation was performed. Scores of the resulting factors as well as knowledge were compared between the groups. Finally, group membership was predicted with scores of the factors and knowledge using logistic regression. This analysis was conducted to compare the specific value of each predictor controlling the influence of all other predictors.

\section{Results}

Of 1,786 individuals approached by telephone, 308 between 55 and 79 years of age agreed to participate and completed the survey by structured telephone interview. Of these, 136 were without previous screening colonoscopy (group A), 103 had previously been screened by colonoscopy (group B), and 55 had undergone a colonoscopy for diagnostic reasons. These 55 along with 14 par- 
Table 1. Demographic data

\begin{tabular}{|c|c|c|c|c|}
\hline & $\begin{array}{l}\text { No colono- } \\
\text { scopy } \\
(\mathrm{n}=136)\end{array}$ & $\begin{array}{l}\text { Previous screen- } \\
\text { ing colonoscopy } \\
(\mathrm{n}=103)\end{array}$ & $\mathrm{p}$ & $\begin{array}{l}\text { Effect- } \\
\text { size }^{1}\end{array}$ \\
\hline Age, years (median; range) & $66 ; 55-79$ & $66 ; 55-79$ & 0.412 & -0.11 \\
\hline Male/female, $\%$ & $39 / 61$ & $40.8 / 59.2$ & 0.791 & 0.02 \\
\hline \multicolumn{5}{|l|}{ Education, \% } \\
\hline High school or lower & 48.1 & 64.7 & & \\
\hline College or higher & 51.9 & 35.3 & 0.012 & 0.16 \\
\hline Have a primary physician ${ }^{2}, \%$ & 80 & 95.1 & 0.001 & 0.22 \\
\hline \multicolumn{5}{|l|}{ Employment, \% } \\
\hline Full-time/part-time & 41.2 & 25.2 & & \\
\hline Retired & 50 & 68.9 & & \\
\hline Other & 8.8 & 5.8 & 0.013 & 0.19 \\
\hline \multicolumn{5}{|l|}{ Health insurance, $\%$} \\
\hline Statutory & 69.6 & 76.7 & & \\
\hline Private & 30.4 & 23.3 & 0.243 & 0.08 \\
\hline \multicolumn{5}{|c|}{$\begin{array}{l}{ }^{1} \text { Effect size for age was calculated based on } \mathrm{t} \text { test with } \mathrm{d} \text { values of } 0.2-0.5,0.5-0.8 \text {, } \\
\text { and }>0.8 \text { indicating small, medium, and large differences, respectively. Effect sizes for } \\
\text { all other variables were calculated based on } \chi^{2} \text { tests with w values of } 0.1-0.3,0.3-0.5 \text {, and } \\
>0.5 \text { indicating small, medium, and large differences, respectively. } \\
{ }^{2} \text { Seen within the last } 12 \text { months. }\end{array}$} \\
\hline
\end{tabular}

ticipants with a personal history of colorectal cancer or chronic inflammatory bowel disease were excluded from further analysis. The median age of both groups was 66 years (range 55-79). There was no significant difference in sex distribution and health insurance status between the two groups (table 1). However, individuals without prior screening colonoscopy were more likely to have a higher degree of education and to be employed compared to the screened group ( $\mathrm{p}=0.012$ and $\mathrm{p}=0.013$, respectively). Remarkably, only $80 \%$ of non-screened compared to $95 \%$ of screened individuals reported to have a primary physician $(\mathrm{p}=0.001)$. This difference in affiliation with a primary physician is further supported by the fact that only $28 \%$ of the non-screened but $58 \%$ of the screened group stated that they had previously received a recommendation by their primary physician to undergo screening colonoscopy.

To identify factors that influence participation in screening, colonoscopy questions in the four categories 'concerns about colonoscopy', 'knowledge about colonoscopy and colorectal cancer', 'attitude to health and healthy lifestyle', and 'extended personal experience with colorectal cancer and colonoscopy' were posed. Both groups equally frequently mentioned bowel preparation as a major concern and there was no difference in terms of worries about unfavorable results from a colonoscopy (table 2). The feeling of embarrassment by colo- noscopy differed slightly between the groups ( $p=0.040$ ). But 23 and $36 \%$ of the non-screened versus 4 and $8 \%$ of the screened group reported to be afraid of discomfort or complications caused by colonoscopy ( $p<0.001$ and $\mathrm{p}<0.001$, respectively). However, no differences between the two groups were identified concerning knowledge about colorectal cancer and efficacy of colonoscopy-based screening. Nutrition and physical activity were rated as important by the majorities of both groups. In contrast to primary prevention, both groups differed significantly in terms of their attitude to secondary prevention. 93 and $80 \%$ of the screened but only 47 and $46 \%$ of the non-screened group rated screening examinations and consultations with a physician concerning screening as important $(\mathrm{p}<0.001$ and $\mathrm{p}<0.001$, respectively). Accordingly, 96 and $93 \%$ of the screened but only 59 and $63 \%$ of the non-screened had previously had a FOBT or any other screening procedures (Papanicolaou smear, mammography, rectal digital examination, PSA testing) performed ( $\mathrm{p}<0.001$ and $\mathrm{p}<0.001)$. In this context, $50 \%$ of the non-screened had an obvious misconception of screening as a measure to identify subclinical disease, as to their opinion a screening colonoscopy should only be performed in case of complaints. Previous experience of members of their own social environment was another important influencing factor. We found that individuals without prior colonoscopy 
Table 2. Factors that influence participation in screening colonoscopy (95\% CI)

\begin{tabular}{|c|c|c|c|c|}
\hline & $\begin{array}{l}\text { No colonoscopy } \\
(\mathrm{n}=136)\end{array}$ & $\begin{array}{l}\text { Previous screening } \\
\text { colonoscopy }(n=103)\end{array}$ & $\mathrm{p}$ & Effect size $^{1}$ \\
\hline \multicolumn{5}{|l|}{ Concerns about colonoscopy, \% } \\
\hline Worried about bowel preparation & $44.9 ; 36.5-53.3$ & $44.7 ; 35.1-54.3$ & 1.0 & 0.00 \\
\hline Embarrassed by procedure & $14.3 ; 8.4-20.2$ & $5.9 ; 1.3-10.4$ & 0.040 & 0.13 \\
\hline Afraid of discomfort & $23 ; 15.9-30.1$ & $3.9 ; 0.2-7.6$ & $<0.001$ & 0.26 \\
\hline Afraid of complications & $36.2 ; 28.1-44.3$ & $7.8 ; 2.6-13$ & $<0.001$ & 0.33 \\
\hline Afraid of bad results & $28.2 ; 20.6-35.8$ & $22.3 ; 14.3-30.3$ & 0.366 & 0.07 \\
\hline \multicolumn{5}{|l|}{ Knowledge, \% } \\
\hline Correct estimation of incidence of CRC & $24.3 ; 17.1-31.5$ & $25.2 ; 16.8-33.6$ & 0.881 & 0.06 \\
\hline Correct estimation of efficacy of early detection & $16.2 ; 10-22.4$ & $24.3 ; 16-32.6$ & 0.140 & 0.10 \\
\hline \multicolumn{5}{|l|}{ Attitude to health, $\%$} \\
\hline Nutrition is important & $75.7 ; 68.5-82.9$ & $84.5 ; 77.5-91.5$ & 0.108 & 0.11 \\
\hline Physical activity is important & $78.7 ; 71.8-85.6$ & $82.4 ; 75-89.8$ & 0.514 & 0.05 \\
\hline Screening is important & $47.1 ; 38.7-55.5$ & $93.2 ; 88.2-98.1$ & $<0.001$ & 0.49 \\
\hline Consultation is important & $46.3 ; 37.9-54.7$ & $79.6 ; 71.8-87.4$ & $<0.001$ & 0.34 \\
\hline Prior FOBT screening & $58.5 ; 50.2-66.8$ & $96.1 ; 92.4-99.8$ & $<0.001$ & 0.45 \\
\hline Have had other screening ${ }^{2}$ & $62.5 ; 54.4-70.6$ & $93.2 ; 88.3-98.1$ & $<0.001$ & 0.35 \\
\hline \multicolumn{5}{|l|}{ Family members, friends, colleagues have had, \% } \\
\hline Colorectal cancer & $33.1 ; 25.2-41$ & $45.6 ; 36-55.2$ & 0.060 & 0.13 \\
\hline Colonoscopy & $53.3 ; 44.9-61.7$ & $74.8 ; 66.4-83.2$ & 0.001 & 0.22 \\
\hline
\end{tabular}

were less likely to be aware of a family member, friend, or colleague who had previously been diagnosed with colorectal cancer ( 33 vs. $46 \%$; $\mathrm{p}=0.060$ ) or someone who had undergone colonoscopy (53 vs. $75 \%$; $p<0.001$ ) than members of the screened group.

A PCA (Varimax rotation) was performed in order to combine items [17]. The knowledge questions were excluded from this analysis due to different answer formats. This analysis identified the three factors 'primary prevention', 'secondary prevention', and 'concerns about colonoscopy' (table 3). The loadings of the factors primary and secondary prevention can be considered as high and characteristic for the assessed domains. The loadings for the factor concern are moderate to high. Based on the results of the PCA, mean scores for each of the three scales as well as a sum score for the knowledge questions were calculated (table 4). Comparison of the means of these scores revealed a strong and significant effect concerning the attitude to secondary prevention $(\mathrm{p}<0.01)$. The differences were smaller but also significant for the scales concerns about colonoscopy $(\mathrm{p}=0.012)$ and knowledge $(\mathrm{p}<0.001)$. The scale primary prevention showed no significant $(\mathrm{p}=0.12)$ difference.

Acceptance of Screening Colonoscopy
Table 3. Grouping of factors influencing participation in screening colonoscopy

\begin{tabular}{llll}
\hline & Concerns & $\begin{array}{l}\text { Secondary } \\
\text { prevention }\end{array}$ & $\begin{array}{l}\text { Primary } \\
\text { prevention }\end{array}$ \\
\hline Nutrition & & & 0.81 \\
Physical activity & & & 0.85 \\
Screening & & 0.88 & \\
Consultation & & 0.87 & \\
Preparation & 0.46 & & \\
Embarrassment & 0.59 & & \\
Discomfort & 0.50 & & \\
Complication & 0.73 & & \\
Result & 0.68 & & \\
\end{tabular}

Loadings $<0.30$ are omitted.

A logistic regression was conducted with group membership as the dependent variable. Knowledge as well as the three PCA-based factors served as predictors. This multivariate analysis revealed that concerns about colonoscopy $(\mathrm{p}=0.026)$ and participation in measures of sec-

Digestion 2010;81:120-126 
Table 4. Mean comparison and logistic regression

\begin{tabular}{|c|c|c|c|c|c|c|c|}
\hline & & \multicolumn{2}{|c|}{ Mean comparison } & \multicolumn{4}{|c|}{ Logistic regression } \\
\hline & & mean $\pm \mathrm{SD}^{1}$ & $\mathrm{p}$ & Effect size $^{2}$ & $\mathrm{~B}$ & SE & $\mathrm{p}$ \\
\hline Primary prevention & $\begin{array}{l}\text { no colonoscopy } \\
\text { colonoscopy }\end{array}$ & $\begin{array}{l}3.15 \pm 0.82 \\
3.32 \pm 0.72\end{array}$ & 0.12 & -0.22 & 0.18 & 0.17 & 0.30 \\
\hline Secondary prevention & $\begin{array}{l}\text { no colonoscopy } \\
\text { colonoscopy }\end{array}$ & $\begin{array}{l}2.57 \pm 1.08 \\
3.58 \pm 0.68\end{array}$ & $<0.001^{3}$ & -0.95 & 1.18 & 0.20 & $<0.001$ \\
\hline Concerns & $\begin{array}{l}\text { no colonoscopy } \\
\text { colonoscopy }\end{array}$ & $\begin{array}{l}1.94 \pm 0.83 \\
1.72 \pm 0.54\end{array}$ & $0.012^{3}$ & 0.30 & -0.42 & 0.19 & 0.026 \\
\hline Knowledge & $\begin{array}{l}\text { no colonoscopy } \\
\text { colonoscopy }\end{array}$ & $\begin{array}{l}3.08 \pm 1.12 \\
3.62 \pm 1.07\end{array}$ & $<0.001$ & -0.48 & 0.19 & 0.16 & 0.243 \\
\hline
\end{tabular}

$\mathrm{SD}=$ Standard deviation; $\mathrm{d}$ = effect size for the difference between both groups (standardized on total SD); $\mathrm{B}=$ regression weight; $\mathrm{SE}=$ standard error.

${ }^{1}$ Potential min./max. values for concerns, secondary prevention, primary prevention 1.0/4.0, and for knowledge 0.0/6.0.

${ }^{2}$ Effect sizes were calculated based on $t$ test with d values of $0.2-0.5,0.5-0.8$, and $>0.8$ indicating small, medium, and large differences, respectively.

${ }^{3}$ Corrected for inhomogeneous variances.

ondary prevention $(\mathrm{p}<0.001)$, but neither knowledge about colorectal cancer and screening nor primary prevention were significant predictors of group membership (table 4). Finally, the combined impact of all four predictors for participation in screening colonoscopy was determined using Nagelkerke's $R^{2}$ [18]. We found that all four variables together explained $33 \%$ of the differences between the two groups. This effect can be considered as large. In summary, attitude towards secondary prevention and concerns about colonoscopy are the single most important predictors of participation in colonoscopy screening after controlling for mutual influence of all predictors.

\section{Discussion}

A screening colonoscopy program was implemented in Germany in October 2002. So far the cumulative participation rate of eligible average-risk persons aged $\geq 55$ years is low. The key to improve compliance with colorectal cancer screening lies in understanding factors which influence participation of the population to be screened. Most studies analyzing the reasons for low participation in colon cancer screening have been performed in the USA $[15,19-22]$. This study was prompted by the fact that at the time of the survey, no data were available on factors influencing participation in colonoscopy screening in
Germany. Our study identified demographic factors, concerns about colonoscopy, and the general attitude to screening as important predictors of adherence to the German screening recommendations.

Our data suggest that a typical individual undergoing screening colonoscopy is unemployed or retired, has a lower degree of education and is very likely to have a primary physician. However, people with a higher education and those with a better health status might tend to work longer during their lifetimes and might therefore neither be in need nor have the time to regularly see a doctor and to undergo a screening colonoscopy. As they see a doctor less frequently they might have less chance to be informed about screening procedures and to receive the recommendation to undergo colonoscopy screening. This reveals the pivotal role of primary physicians in informing and motivating patients for screening colonoscopy as has already been reported in previous studies [21,23,24]. Our findings stand in contrast to other studies concerning the role of education in terms of participation in screening colonoscopy $[14,25]$. Those studies found that higher levels of education correlated with higher participation rates in screening programs. The reason for these different findings is most likely due to the limited representativeness of all available studies. Therefore, future studies need to explore the role of education in this context in more detail. 
An association between participation in screening colonoscopy and other measures of cancer screening has also been reported previously. Several studies have reported that women having undergone a Papanicolaou smear and a mammography within the past year were more likely to having had a screening colonoscopy performed [26-28]. Interestingly, there was no significant difference between both groups in terms of primary prevention and healthy lifestyle, an attitude that usually is independent of consultations with the primary physician. However, the effect size indicates that individuals who have undergone colonoscopy pay greater attention to primary prevention.

Perception of colonoscopy in the group of persons who had never before been screened was worse than in the group of persons who had previously undergone screening colonoscopy. This suggests that information about the colonoscopic procedure itself in order to remove irrational fears of discomfort and complications is an important issue influencing participation in colorectal cancer screening. In contrast, embarrassment by colonoscopy and worries about a potentially unfavorable diagnosis were not rated differentially between both groups. However, similar as in other reports, our survey also identified concerns about large bowel preparation prior to colonoscopy as a major deterrent irrespectively of the colonoscopy status $[19,29]$. This clearly demonstrates that detailed information about the endoscopic procedure, the opportunity of analgo-sedation, and the low risk of complications should be openly discussed in order to improve the perception of colonoscopy in the public.

To which extent the results of this survey including the sample's representativeness regarding demographic variables can be generalized to other areas of Germany can only be established empirically. Therefore, future studies should draw larger samples and perform interviews in different regions of Germany. Furthermore, larger studies would be able to investigate the influence of gender as has been reported before [30]. We addressed potential influencing factors with a relatively small number of items in order to receive a high compliance with the survey. This might be associated with a small inconsistency. Consequently, future studies should ideally lengthen the survey to increase reliability [31]. However, this might result in lower rates of completed interviews, which in turn might represent a new confounding factor. Of the 1,786 individuals approached by telephone, only 728 agreed to complete the interview. This rate might be viewed as low and suspected to confound the results. However, empirical evidence suggests that the response rate does not neg- atively affect the accuracy of a survey [32]. The form of questioning is another critical issue. In this study, telephone interviews were used which might be more prone to incorrect or distorted answers than face-to-face interviews. Consequently, future research should invest some effort into replicating findings using different questioning formats.

The reasons for the low adherence to screening colonoscopy in Germany have not been well understood so far. Our study identified previous participation in other measures of secondary prevention and concerns about colonoscopy as independent critical factors deterring from screening colonoscopy. Together with the attitude to primary prevention and knowledge about colorectal cancer, these factors explain 33\% of the differences between the groups of previously screened and unscreened people. This suggests that future campaigns aiming at increasing the adherence to the German colonoscopy screening program and most likely also in other countries should actively discuss the frequent concerns about colonoscopy such as bowel preparation, pain and discomfort during colonoscopy, as well as the fear of complications. Except for bowel preparation, information about sedation during colonoscopy and the very low rate of severe complications should help increase the reputation of colonoscopy. Moreover, primary care physicians have a very central role in guiding their patients to measures of secondary prevention including colonoscopy. Appreciation of this role of primary physicians to inform and motivate their patients to screening colonoscopy should be accompanied by appropriate compensations for invested time and effort.

\section{Acknowledgement}

The authors thank Combitel, Gesellschaft für Dialog-Marketing, Munich, Germany, for technical support with the telephone interviews. 


\section{References}

1 Jemal A, Siegel R, Ward E, Hao Y, Xu J, Murray $\mathrm{T}$, Thun $\mathrm{MJ}$ : Cancer statistics, 2008. CA Cancer J Clin 2008;58:71-96.

2 Selby JV, Friedman GD, Quesenberry CPJ, Weiss NS: A case-control study of screening sigmoidoscopy and mortality from colorectal cancer. N Engl J Med 1992;326:653-657.

3 Winawer SJ, Zauber AG, Ho MN, O’Brien MJ, Gottlieb LS, Sternberg SS, Waye JD, Schapiro M, Bond JH, Panish JF, et al: Prevention of colorectal cancer by colonoscopic polypectomy. The National Polyp Study Workgroup. N Engl J Med 1993;329:19771981.

4 Imperiale TF, Wagner DR, Lin CY, Larkin GN, Rogge JD, Ransohoff DF: Risk of advanced proximal neoplasms in asymptomatic adults according to the distal colorectal findings. N Engl J Med 2000;343:169-174.

5 Lieberman DA, Weiss DG, Bond JH, Ahnen DJ, Garewal H, Chejfec G: Use of colonoscopy to screen asymptomatic adults for colorectal cancer. Veterans Affairs Cooperative Study Group 380. N Engl J Med 2000; 343:162-168.

6 Mandel JS, Bond JH, Church TR, Snover DC, Bradley GM, Schuman LM, Ederer F: Reducing mortality from colorectal cancer by screening for fecal occult blood. Minnesota Colon Cancer Control Study. N Engl J Med 1993;328:1365-1371.

7 Kahi CJ, Rex DK, Imperiale TF: Screening, surveillance, and primary prevention for colorectal cancer: a review of the recent literature. Gastroenterology 2008; $135: 380-$ 399

8 Levin B, Lieberman DA, McFarland B, Andrews KS, Brooks D, Bond J, Dash C, Giardiello FM, Glick S, Johnson D, Johnson CD, Levin TR, Pickhardt PJ, Rex DK, Smith RA, Thorson A, Winawer SJ: Screening and surveillance for the early detection of colorectal cancer and adenomatous polyps, 2008: a joint guideline from the American Cancer Society, the US Multi-Society Task Force on Colorectal Cancer, and the American College of Radiology. Gastroenterology 2008; 134:1570-1595.

9 Pignone M, Rich M, Teutsch SM, Berg AO, Lohr KN: Screening for colorectal cancer in adults at average risk: a summary of the evidence for the US Preventive Services Task Force. Ann Intern Med 2002;137:132-141.
10 Rex DK, Johnson DA, Lieberman DA, Burt RW, Sonnenberg A: Colorectal cancer prevention 2000: screening recommendations of the American College of Gastroenterology. American College of Gastroenterology. Am J Gastroenterol 2000;95:868-877.

11 Schmiegel W, Pox C, Adler G, Fleig W, Folsch UR, Fruhmorgen P, Graeven U, Hohenberger W, Holstege A, Kuhlbacher T, Porschen R, Propping P, Riemann JF, Sauer R, Sauerbruch T, Schmoll HJ, Zeitz M, Selbmann HK S3-guideline conference 'Colorectal Cancer' 2004 (in German). Dtsch Med Wochenschr 2005;130(suppl 1):S5-S53.

12 www.zi-berlin.de: Wissenschaftliche $\mathrm{Be}$ gleitung der Früherkennungs-Koloskopie. Jahresbericht. http://www.zi-berlin.de/ koloskopie/downloads/Jahresbericht_ 2006 and http://www.zi-berlin.de/koloskopie/downloads/Musterbericht_Koloskopie_Feedback_2006.pdf. 2006.

13 Lieberman DA: Cost-effectiveness model for colon cancer screening. Gastroenterology 1995;109:1781-1790.

14 Janz NK, Wren PA, Schottenfeld D, Guire KE: Colorectal cancer screening attitudes and behavior: a population-based study. Prev Med 2003;37:627-634.

15 Seeff LC, Nadel MR, Klabunde CN, Thompson T, Shapiro JA, Vernon SW, Coates RJ: Patterns and predictors of colorectal cancer test use in the adult US population. Cancer 2004;100:2093-2103.

16 Thorpe LE, Mostashari F, Hajat A, Nash D, Karpati A, Weber T, Winawer S, Neugut AI, Awad A, Zevallos M, Remy P, Frieden T: Colon cancer screening practices in New York City, 2003: results of a large random-digit dialed telephone survey. Cancer 2005; 104: 1075-1082.

17 Horn JL: A rationale and test for the number of factors in factor analysis. Psychometrika 1965;30:179-185.

18 Howell D: Statistical Methods for Psychology. Belmont, Wadsworth Publishing Company, 2007.

19 Harewood GC, Wiersema MJ, Melton L Jr: A prospective, controlled assessment of factors influencing acceptance of screening colonoscopy. Am J Gastroenterol 2002;97:31863194.

20 Lewis SF, Jensen NM: Screening sigmoidoscopy. Factors associated with utilization. Gen Intern Med 1996;11:542-544.
21 Vernon SW, Myers RE, Tilley BC: Development and validation of an instrument to measure factors related to colorectal cancer screening adherence. Cancer Epidemiol Biomarkers Prev 1997;6:825-832.

22 Wee CC, McCarthy EP, Phillips RS: Factors associated with colon cancer screening: the role of patient factors and physician counseling. Prev Med 2005;41:23-29.

23 Farraye FA, Wong M, Hurwitz S, Puleo E, Emmons K, Wallace MB, Fletcher RH: Barriers to endoscopic colorectal cancer screening: are women different from men? Am J Gastroenterol 2004;99:341-349.

24 Ruffin MT, Gorenflo DW, Woodman B: Predictors of screening for breast, cervical, colorectal, and prostatic cancer among community-based primary care practices. J Am Board Fam Pract 2000;13:1-10.

25 Rozen P, Young GP, Levin B, Spann SJ: Colorectal Cancer in Clinical Practice. Prevention, Early Detection and Management. London, Dunitz, 2002.

26 Mandelson MT, LaCroix AZ, Anderson LA, Nadel MR, Lee NC: Comparison of self-reported fecal occult blood testing with automated laboratory records among older women in a health maintenance organization. Am J Epidemiol 1999;150:617-621.

27 Mayer-Oakes SA, Atchison KA, Matthias RE, De Jong FJ, Lubben J, Schweitzer SO: Mammography use in older women with regular physicians: what are the predictors? Am J Prev Med 1996;12:44-50.

28 Shapiro J, Prislin PM, Hanks C, Lenahan P: Predictors of psychosocial teaching styles in a family practice residency program. Fam Med 2001;33:607-613.

29 Beebe TJ, Johnson CD, Stoner SM, Anderson KJ, Limburg PJ: Assessing attitudes toward laxative preparation in colorectal cancer screening and effects on future testing: potential receptivity to computed tomographic colonography. Mayo Clin Proc 2007;82:666671.

30 Sieverding M, Matterne U, Ciccarello L: Gender differences in FOBT use: evidence from a large German survey. Z Gastroenterol 2008;46(suppl 1):S47-S51.

31 Bühner M: Introduction to Test and Questionnaire Construction. Munich, Pearson, 2006.

32 Krosnick JA: Survey research. Annu Rev Psychol 1999;50:537-567. 